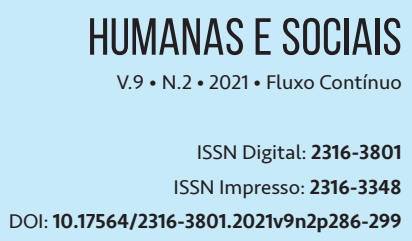

\section{PROVEDORA OU CONTRIBUINTE: PERCEPÇÕES DO RENDIMENTO DO TRABALHO NO MUNICÍPIO DE PARAUAPEBAS, PARÁ, AMAZÔNIA}

PROVIDER OR CONTRIBUTOR/TAXIPAYER: PERCEPTIONS ABOUT YIELD FOR WORK IN PARAUAPEBAS, PARÁ, AMAZON

PROVEEDORA O CONTRIBUYENTE: PERCEPCIONES DEL INGRESO DEL TRABAJO EN PARAUAPEBAS, PARÁ, AMAZONIA

Daniela Castro dos Reis ${ }^{1}$ Josilene Ferreira Mendes ${ }^{2}$ Ana Carolina Carneiro de $\mathrm{Abreu}^{3}$

\section{RESUMO}

Este estudo tem como objetivo discutir a percepção de mulheres trabalhadoras sobre seu rendimento do trabalho na composição da renda familiar se como provedora ou contribuinte no Município de Parauapebas, Estado do Pará, Amazônia. Participaram da pesquisa 190 indivíduos entre homens e mulheres divididos por faixa etária, aplicando-se questionário com 21 perguntas abertas e fechadas. Os dados levantados foram analisados por meio do software SPSS-20 e apresentados em tabelas. $\mathrm{Na}$ perspectiva da divisão sexual do trabalho, dos papéis sociais de homem e de mulher na sociedade e de novos arranjos familiares, percebeu-se que mesmo as mulheres solteiras se autodeclararam como contribuintes, refletindo que não se trata de um aspecto meramente econômico, mas cultural.

\section{PALAVRAS-CHAVE}

Provedora. Contribuinte. Papel Social. 


\section{ABSTRACT}

The objective of this study is to discuss the perception of working women about their work income in the composition of family income if as a provider or contributor in the city of Parauapebas, State of Pará, Amazon. Participated in the study 190 individuals between men and women divided by age group, questionnaire with 21 open and closed questions. The collected data were analyzed through the software SPSS-20 and presented in tables. In the perspective of the sexual division of labor, the social roles of men and women in society, and new family arrangements, it was perceived that even single women self-declared themselves as taxpayers, reflecting that it is not a merely economic but cultural aspect.

\section{KEYWORDS}

Provider. Contributor. Social role.

\section{RESUMEN}

Este estudio tuvo como objetivo discutir la percepción de las mujeres trabajadoras sobre su rendimiento del trabajo en la composición del ingreso familiar si como proveedora o contribuyente del municipio de Parauapebas, Estado de Para, Amazonia. Participaron en la investigación 190 individuos entre hombres y mujeres divididos por grupos de edad con aplicación de un cuestionario con 21 preguntas abiertas y cerradas. Los datos obtenidos fueran analizados con el software SPSS-20 y presentados en tablas. En la perspectiva de la división sexual del trabajo, los papeles sociales del hombre y de la mujer en la sociedad, y de nuevos esquemas familiares, si observó que mismo las mujeres solteras si auto declararán como contribuyentes presentando que no sólo es un aspecto simplemente económico, sino cultural.

\section{PALABRAS CLAVE}

Proveedora. Contribuyente. Papel social. 


\section{INTRODUÇ̧̃̃o}

A concepção acerca do papel da mulher na sociedade e sobretudo no mercado de trabalho tem sido alvo de inúmeros estudos (BERTOLINI, 2001; GARCIA, 2001; PRESTON, ROSE, NORCLIFFE; HOLMES, 2000; ARRIGHI; MAUME, 2000; BABIUK, 2015), tais contribuições ajudam a compreender 0 papel social da mulher no passado histórico e sua evolução na sociedade atual.

Tais pesquisas buscam compreender a transformação, mesmo que gradual, do rompimento do paradigma: homem provedor e mulher dona de casa. Desse modo, este artigo tem como objetivo discutir as percepções de mulheres trabalhadoras no Município de Parauapebas, Estado do Pará, considerando a sua contribuição financeira no sustento de suas famílias e o reflexo da compreensão de seu papel social no seio familiar.

A discussão sobre o papel (ou papéis) da mulher neste artigo será conduzida pelos conceitos de contribuintes e provedoras. Tais conceitos adotados revelam o grau de contribuição econômica, ambos relacionados ao sustento da família tendo como parâmetro o gênero: o termo contribuinte é aquele que tem uma parcela de participação em determinado fim, neste caso auxílio ao sustento da família; e o provedor, aquele que fornece ou abastece algo ou alguém, representando um papel central, neste caso o provedor da família.

A discussão dos papeis (contribuinte/provedor), principalmente da mulher na sociedade brasileira está localizada em bases sócio-históricas. Este cenário promove a reflexão de como a mulher se constituiu, desempenhando o papel de trabalhadora no mercado de trabalho e o seu lugar diante da divisão sexual do trabalho, demonstrando, assim, a evolução sociológica do papel da mulher contribuinte e provedora na sociedade brasileira atual.

Desafios foram postos à mulher na busca de sua inserção no mercado de trabalho, principalmente os relativos aos direitos até então renegados a ela: sociais e econômicos e devido às lutas de movimentos sociais e avanços no debate teórico, alguns autores(as) problematizam a divisão sexual do trabalho (ARAÚJO, 2017).

No Brasil, no século XX, segundo Fleck e Wagner (2003) o modelo de família tradicional da classe média brasileira acompanhava uma tendência mundial com uma clara divisão de papéis: o homem, o patriarca, com o papel de prover a família a partir de seu trabalho remunerado, enquanto a mulher assumia os afazeres domésticos.

A necessidade desta abordagem destaca-se, sobretudo, porque na divisão sexual do trabalho, as mulheres além de assumirem postos no mercado de trabalho ainda têm outro papel (trabalho) na esfera privada: a realização dos afazeres domésticos como o cuidado com a casa e dos filhos. Melo, Considera e Di Sabbato (2007) destacam que a realização desses afazeres domésticos configura como trabalho, visto que analisaram a importância do trabalho doméstico tanto pelo impacto na economia brasileira quanto no bem-estar das pessoas.

Em relação à divisão sexual do trabalho, Hirata e Kergoat (1994) há tempos já ressaltavam a necessidade de estudos da classe operária a partir do fator sexo ou gênero dos atores sociais que a compõem, visto que a maioria dos estudos abordava esta classe como homogênea sem distinção social entre seus papéis. 
Nesta perspectiva histórica, Melo e Thomé (2018, p. 87) destacam que “a divisão sexual do trabalho foi abalada com a entrada massiva das mulheres na escola e no mercado de trabalho, a partir dos anos 1970", o que refletiu em novos arranjos familiares e no crescimento da participação econômica da muther no sustento da família, todavia, são processos de mudanças lentos e ocorrem de forma não linear.

De acordo com as Estatísticas de Gênero do Instituto Brasileiro de Geografia e Estatística (IBGE, 2018), em 2016 as mulheres dedicaram aos cuidados de terceiros e/ou afazeres domésticos aproximadamente $73 \%$ a mais de horas comparado aos homens. Na região Norte do Brasil, as mulheres dedicaram em média 17,2 horas semanais aos cuidados e/ou afazeres domésticos comparados às 10,2 horas semanais dos homens.

Diante da invisibilidade sócio-histórica da mulher e seu lugar cativo na esfera doméstica, o homem ocupa papel central no sustento da sua família mesmo que a sua renda não seja superior ao da sua parceira. Este aspecto reflete os papéis estabelecidos, que não se trata, necessariamente, do aspecto econômico, mas do papel social de cada um deles reforçado pela divisão sexual do trabalho. Nesse sentido, Narvaz e Koller (2006) destacam que, no Brasil, o trabalho feminino foi regulamentado a partir da promulgação da Consolidação das Leis do Trabalho em 1941, mas somente em 1962 que o Código Civil permitiu que as mulheres pudessem trabalhar sem ter que pedir autorização aos seus maridos.

A Organização Internacional do Trabalho (OIT, 2018), a partir de dados sobre as perspectivas sociais e de emprego no mundo para as mulheres, apresenta que mesmo aquelas que conseguem ingressar no mercado de trabalho têm acesso limitado. As oportunidades de emprego de qualidade são menores, decorrente por vezes da escolha do tipo de trabalho com horários mais flexíveis. $\mathrm{Na}$ proporção entre o trabalho remunerado, o emprego, e o não remunerado como tarefas domésticas e cuidados com terceiros, as mulheres possuem carga horária superior no trabalho não remunerado, penalizando-as na escolha do emprego formal.

Marri e Wajnman (2007) ressaltam que mesmo naquelas famílias em que as esposas possuem rendimentos superiores do que seus cônjuges, figurando como principal provedora da família, isso não as isenta dos afazeres domésticos. Independente da participação financeira da mulher no sustento da família o trabalho doméstico será sempre relegado a ela.

Ainda na pesquisa de Fleck e Wagner (2003) apesar de as mulheres contribuírem com a maior parte da renda, os homens não assumiam a responsabilidade pela esfera doméstica da mesma forma que as mulheres passaram a assumir a condição de principal provedora do sustento.

A mulher ainda se sentia responsável por esses cuidados, necessitando conciliar, constantemente, as demandas das esferas pública e privada. Ao passo que o homem permitia-se buscar um espaço individual, não abdicando de seus momentos de lazer, dessa forma, a mulher sentia culpa e não se permitia abandonar, mesmo que temporariamente, seu papel predominantemente materno. Tais constatações corroboram os dados de Babiuk (2015) que estudou as famílias monoparentais, nas quais a mulher assume sozinha, a diversificação de papéis, encarregando-se de todas as funções inclusive de provedora da família.

Montali (2006) analisou os rearranjos familiares com a inserção da mulher no mercado de trabalho, a precarização das relações de trabalho e desemprego, utilizando a terminologia de mulheres "provedo- 
ras" e "co-provedoras". A autora estabeleceu a diferenciação da contribuição financeira das mulheres cônjuges e chefes-de-família em seu núcleo familiar no período de 1990 a 2003 no Estado de São Paulo e constatou que a inserção das mulheres no mercado de trabalho no período compreendido gerou um impacto positivo, isto é, a contribuição do rendimento das mulheres, mesmo as coprovedoras, para a composição da renda familiar, inclusive atenuando no empobrecimento dessas famílias.

Algumas pesquisas como Bertolini (2001), Garcia (2001), Preston, Rose, Norcliffe e Holmes (2000), Arrighi e Maume (2000), Babiuk (2015), têm auxiliado a desvelar como o papel assumido pelas mulheres tem repercutido na dinâmica familiar, nas questões conjugais, bem como, na educação dos filhos. Dessa forma, talvez um dos aspectos mais desafiadores a ser mencionado envolva a necessidade de essas mulheres conciliarem as funções familiares com as acadêmicas e as profissionais.

Fleck e Wagner (2003) identificaram em seu estudo que a manutenção de muitos papéis, funções e atitudes para cada um dos gêneros, indica que a estrutura familiar, neste nível socioeconômico-cultural, ainda está calcada em um modelo tradicional de conceber e representar suas relações. Esses aspectos podem apontar que, apesar de já se perceberem algumas transformações nos padrões e no funcionamento da família, muitos outros seguem a repetir-se, principalmente pela manutenção de papéis apreendidos e esperados socialmente que delegam funções específicas aos homens e às mulheres.

Nesse sentido, torna-se essencial os dados do Relatório Anual Socioeconômico da Mulher (RASEAM, 2015) sobre a autonomia econômica das mulheres, debate também travado por movimentos feministas ${ }^{4}$ e outras organizações ${ }^{5}$, sustentando que essa autonomia é indispensável para que as mulheres possam prover seu próprio sustento e decidir sobre sua própria vida, uma vez que não se trata somente de independência financeira, mas também na sua inserção no mercado de trabalho e seus rendimentos, a distribuição equitativa dos afazeres domésticos e das atividades de cuidado (BRASIL, 2015).

Apesar das inúmeras transformações como a inserção crescente da mulher no mercado de trabatho e nos arranjos familiares, Melo e Thomé (2018) salientam que cabe ainda às mulheres as atribuições no âmbito privado muito mais que no público, sendo que maternidade e casamento ainda são percebidos como etapas influentes na vida de uma mulher.

\section{MÉTODO}

Esta pesquisa apresentou enfoque quantitativo de uma pesquisa transversal com desenhos exploratório e descritivo, cuja finalidade é conhecer um conjunto de variáveis, uma comunidade ou contexto e identificar a incidência das modalidades ou níveis de uma variável em uma determinada população (SAMPIERI; COLLADO; LUCIO, 2013).

A pesquisa foi realizada no município de Parauapebas, localizado na mesorregião sudeste do Estado do Pará, na região amazônica, onde está situada a Serra dos Carajás. A principal atividade econômica desenvolvida no município é a mineração impulsionada principalmente pelo Projeto Grande Carajás (PGC)

4 A exemplo da Marcha Mundial de Mulheres (MMM).

5 A exemplo da Sempreviva Organização Feminista (SOF). 
iniciado na década de 1980 em consórcio de empresas e hoje impulsionado pela "Vale S/A". O PGC representa um dos pilares dos grandes projetos de desenvolvimento na Amazônia. Esse empreendimento gerou grande fluxo de trabalhadores de todos os lugares do Brasil, sobretudo homens (HÉBETTE, 2004).

Participaram desta pesquisa 190 indivíduos, sendo 102 (53,7\%) entre $20<30$ anos e 87 (45\%) $31<40$ anos, sendo um (0,5\%) sem informação. Entre os indivíduos, 107 (56,31 \%) são do sexo masculino, com média de idade de 32,87, desvio padrão 9,27, sendo a idade mínima 18 anos e idade máxima 58 anos; 83 (43,68\%) são do sexo feminino, com média de idade de 30,71, desvio padrão 12,33, sendo a idade mínima 18 e máxima 58.

Para o levantamento dos dados utilizou-se como instrumento de coleta um questionário com 21 perguntas, sendo quatro perguntas abertas e 17 fechadas. 0 instrumento era composto por duas seções, a primeira com as variáveis sociodemógraficas como escolaridade, nível escolar, profissão, sexo, empresa, função, hora diária de trabalho, idade, status familiar, estado civil, ter filhos, religião, idade que começou a trabalhar e tempo de residência em Parauapebas. A segunda parte composta por perguntas relacionadas às percepções sobre o conceito de trabalho e sobre as percepções desta atividade.

A coleta de dados seguiu etapas pré-determinadas: a primeira determinou-se que o trabalho doméstico seria excluído, por não fazer parte do objeto desta pesquisa; a segunda etapa aplicou-se o Termo de Consentimento e Esclarecido (TCLE) para que o questionário fosse respondido. Todos os questionários foram aplicados por meio de entrevistas semiestruturadas.

Os dados foram armazenados em uma planilha do Excel, na qual foram inseridas as variáveis demográficas e categóricas. Após a filtragem dos dados, o banco de dados foi transformado em variáveis binárias, de maneira que possibilitasse análise mais consistente. Os dados foram analisados no SPSS-20, por meio da estatística descritiva e exploratória, utilizando o Chi-quadrado para análise dos dados. Os dados serão apresentados em tabelas.

\section{RESULTADOS}

Os dados coletados demonstraram a percepção das mulheres sobre a sua participação financeira no sustento da família e, de forma implícita os papéis de homem e de mulher na família. Estes resultados serão apresentados em duas seções, sendo a primeira a caracterização do perfil biosociodemográfico dos participantes e a segunda parte análise dos dados exploratórios, considerando as variáveis, contribuinte e provedor; e sexo e contribuição econômica.

Na caracterização biosociodemográfica foi analisado o perfil dos 190 participantes. Quando analisados os dados de contribuição financeira como ter ou não filho, obteve-se os seguintes resultados: na categoria contribuinte $41(54,2 \%)$ tem filhos e 59 (54,8\%) não tem filhos; na categoria provedor $62(48,2 \%)$ tem filhos, 27 (40,8\%) não tem filhos e 1 Sem informação. Ambas as categorias tinham associação significativa ( $\mathrm{P} \leq 0,01)$.

$\mathrm{Na}$ análise, considerando o sexo, o tipo de contribuição e ter ou não ter filho, identificou-se que 25 mulheres contribuintes tinham filhos e 30 não tinham. Ainda, considerando o sexo feminino, 21 
provedoras tinham filhos e 7 não tinham. Quando se analisa os dados dos homens, percebe-se que 16 contribuintes tinham filhos e 29 não tinham, observando os dados sobre os homens provedores, 41 tinham filhos e 20 não tinham. Todas as categorias associadas tiveram significância $(P \leq 0,01)$.

A análise exploratória analisou três categorias: contribuinte x provedor, sexo e status familiar para avaliar se há uma associação significativa entre o sexo e entre o status familiar. Por serem dados exploratórios, não se pode analisar quais os motivos que levam as mulheres a se perceberem desta forma. Assim, os dados revelaram de uma forma objetiva que as mulheres ainda se percebem como contribuinte e não provedoras.

Os dados da Tabela 1 revelaram que há uma associação entre sexo e a percepção entre ser contribuinte e provedor. Os dados relevaram que 55 do total de 83 mulheres se percebem como contribuintes, total de $59,1 \%$ dos participantes do sexo feminino. Os dados revelaram também que 61 dos 107 homens entrevistados, totalizando (57\%) se percebem como provedor do total de homens.

Tabela 1 - Demonstrativo dos dados descritivos do chi-quardrado

\begin{tabular}{ccccc}
\hline Sexo & Contribuinte & Provedor & SI & Total \\
\hline F & 55 & 28 & 0 & 83 \\
M & 45 & 61 & 1 & 107 \\
\hline Total & 100 & 89 & 1 & 190 \\
\hline
\end{tabular}

Fonte: Dados da pesquisa.

A Tabela 2 demonstra a análise do teste chi-quadrado, revelando associação significativa entre as categorias sexo e tipo de contribuição econômica familiar. Tais achados relevaram que o tipo de contribuição econômica está associado ao sexo dos participantes de maneira significativa com $P \leq 0,003$.

Tabela 2 - Demonstrativo do Teste de chi-quadrado para as variáveis sexo e tipo de contribuição econômica familiar

\begin{tabular}{cccc}
\hline & Valor & df & Sig. Assint. (2 lados) \\
\hline Chi-quadrado de Pearson & $11,386^{\mathrm{a}}$ & 2 &, 003 \\
Razão de probabilidade & 11,881 & 2 &, 003 \\
Associação Linear por Linear & 1,226 & 1 &, 268 \\
$\mathrm{~N}$ de Casos Válidos & 190 & & \\
\hline
\end{tabular}

2 células (33,3\%) esperam contagem menor do que 5. A contagem mínima esperada é, 44.

Fonte: Dados da pesquisa.

Além da análise dos dados da associação entre o tipo de contribuição econômica e sexo, optou-se em avaliar três variáveis e verificar se elas estavam associadas. Os dados conforme Tabela 3 releva- 
ram que 33 mulheres casadas, se consideram contribuintes, perfazendo um total de $71,73 \%$. Enquanto 36 dos homens casados se percebem provedores, totalizando $72 \%$.

$\mathrm{Na}$ categoria solteiro, os dados revelaram que 22 mulheres se percebem como contribuinte, com um percentual de 59,45\% de mulheres solteiras. Os dados do sexo masculino demonstraram que 31 dos solteiros se percebem como contribuintes, com um total de $54,3 \%$.

Tabela 3 - Demonstrativo das variáveis Sexo e Status familiar e Estado Civil Tabulação cruzada

\begin{tabular}{|c|c|c|c|c|c|c|}
\hline \multirow{2}{*}{\multicolumn{3}{|c|}{ Estado Civil }} & \multicolumn{3}{|c|}{ Tipo de contribuição econômica } & \multirow{2}{*}{ Total } \\
\hline & & & Contri & Prove & SI & \\
\hline \multirow{3}{*}{ Casado } & \multirow{2}{*}{ Sexo } & $\mathrm{F}$ & 33 & 13 & - & 46 \\
\hline & & M & 14 & 36 & - & 50 \\
\hline & \multicolumn{2}{|c|}{ Total } & 47 & 49 & - & 96 \\
\hline Solteiro & Sexo & $\begin{array}{l}F \\
M\end{array}$ & $\begin{array}{l}22 \\
31 \\
53\end{array}$ & $\begin{array}{l}15 \\
25 \\
40\end{array}$ & $\begin{array}{l}- \\
1 \\
1\end{array}$ & $\begin{array}{l}37 \\
57 \\
94\end{array}$ \\
\hline
\end{tabular}

Fonte: Dados da pesquisa.

Os dados analisados, considerando as três categorias, só foi significativo para a categoria casada, com um $\mathrm{P} \leq 0,001$. Os dados da categoria solteiros não demonstraram significância conforme Tabela 4 .

Tabela 4 - Demonstrativo do Teste de chi-quadrado para as variáveis: sexo e tipo de contribuição econômica e estado civil

\begin{tabular}{|c|c|c|c|c|c|c|}
\hline & Estado Civil & Valor & df & $\begin{array}{l}\text { Sig. Assint. } \\
\text { (2 lados) }\end{array}$ & $\begin{array}{l}\text { Sig exata } \\
\text { (2 lados) }\end{array}$ & $\begin{array}{c}\text { Sig exata } \\
\text { (1 lado) }\end{array}$ \\
\hline \multirow{5}{*}{ Casado } & Chi-quadrado de Pearson & $18,342 b$ & 1 & ,000 & \multirow{10}{*}{,000 } & \multirow{10}{*}{,000 } \\
\hline & Correção de continuidadec & 16,633 & 1 & ,000 & & \\
\hline & Razão de probabilidade & 18,970 & 1 & ,000 & & \\
\hline & Fisher's Exact Test & & & & & \\
\hline & Associação Linear por Linear & 18,151 & 1 & ,000 & & \\
\hline \multirow{5}{*}{ Solteiro } & N de Casos Válidos & 96 & & & & \\
\hline & Chi-quadrado de Pearson & ,810d & 2 & ,667 & & \\
\hline & Razão de probabilidade & 1,161 & 2 &, 560 & & \\
\hline & Associação Linear por Linear & 679 & 1 & ,410 & & \\
\hline & $\mathrm{N}$ de Casos Válidos & 94 & & & & \\
\hline
\end{tabular}

a. 2 células (33,3\%) esperam contagem menor do que 5 . A contagem mínima esperada é , 44 .

b. 0 células (0,0\%) esperam contagem menor do que 5. A contagem mínima esperada é 22,52.

c. Computado apenas para uma tabela $2 \times 2$

d. 2 células (33,3\%) esperam contagem menor do que 5. A contagem mínima esperada é ,39.

Fonte: Dados da pesquisa. 


\section{DISCUSSÃO}

Os dados acima apresentados demonstram que na relação entre o estado civil (casada ou solteira) e a contribuição financeira por gênero, a maioria das mulheres casadas consideram-se contribuintes e mesmo as mulheres solteiras, em sua maioria consideram-se também no status econômico familiar como contribuintes.

Os resultados demonstraram que mesmo a mulher com filhos e trabalhadora ainda se percebe como contribuinte. Algumas hipóteses podem ser levantadas, tais como a provável internalização do seu papel secundarizado ou ainda por receberem salários menores que seus cônjuges, refletindo a divisão sexual do trabalho (HIRATA; KERGOAT, 1994). Como mulher provedora, a maioria possui filhos, talvez tais participantes se reconheçam como provedoras pelo fator de terem filhos, o que sinaliza uma forte associação do papel da mulher como a cuidadora principal.

Conforme exposto anteriormente, tratando especificamente do Município de Parauapebas, nas décadas 1980 e 1990 houve intensa migração de homens para trabalhar principalmente na atividade de mineração. Rocha (2018) ao descrever o histórico social e cultural do Município relata as relações de gênero conflituosas, quando os migrantes deixavam suas famílias no Nordeste e foram em busca de trabalho e melhores condições de vida na região amazônica, tornando-se "peões de trecho".

0 autor destaca, ainda, que quando esses trabalhadores "caíam na estrada" dificilmente retornavam para seus lares, deixando a responsabilidade de criação dos filhos e sustento da casa com as mulheres. As famílias dos "peões de trecho" que migraram para Parauapebas e foram abandonadas no Município, relataram que tiveram que buscar alternativas para garantir a sobrevivência delas e dos filhos. Desse modo, "a lacuna deixada pelo tradicional provedor seria suprida pela atuação efetiva das mulheres da casa. Mulheres provedoras, e nos dois sentidos: dentro e fora de casa” (ROCHA, 2018, p. 162).

Atualmente, apesar da intensa inserção da mulher no mercado de trabalho e, no caso de Parauapebas, das mulheres trabalhando na mineração, o papel social de contribuinte para a renda familiar perdura, pois naquele contexto citado as mulheres tornavam-se provedoras não por escolha, mas devido ao abandono do provedor. Analisando os dados com associação das variáveis Contribuinte e Provedora a associação entre essas categorias é significativa. Tal constatação corrobora com os estudos de Arrighi, Maume (2000), Babiuk (2015), Grisci, Sawitzki, D’arisbo e Feijó (2016), sobre a internalização dos papéis sociais e da divisão sexual do trabalho.

Entende-se nesta pesquisa a concepção de casado como aquela que é ressaltada na Constituição Federal de 1988, na qual existem vários tipos de família: aquela formada entre duas pessoas que contraíram matrimônio nos termos do Código Civil de 2002 e aqueles que são conviventes em união estável, assim como, a família monoparental, aquela formada por qualquer um dos pais e seus descendentes de acordo com o $\S 4^{\circ}$ do art. 226 da Carta Magna.

$\mathrm{Na}$ análise dos dados para a pesquisa não foi possível investigar em profundidade de investigação para diferenciar o tipo de família para saber se a mulher que se autodeclarou como solteira é na verdade divorciada, ou possui um namorado/convivente, ou está em uma entidade familiar monoparental. Porém, o fato de ser declaradamente solteira e compreender que a sua contribuição financeira 
para a família é de contribuinte implica reafirmar o papel social delegado à mulher na divisão sexual do trabalho que, mesmo oferecendo a principal fonte de renda para sua família, o seu papel é de apenas contribuição para o sustento desta.

Nesse sentido, é necessário considerar a complexidade de arranjos familiares atuais, conforme Melo e Thomé (2018) discutem aos tratar dos padrões de nupcialidade, no qual houve inúmeras mudanças culturais nas últimas décadas no Brasil, refletindo na reconfiguração das características das famílias:

Novas formas de organização das famílias emergiram. Há um elevado número de pessoas morando sozinhas e de pessoas que optam por não ter filhos; há ainda as famílias "tradicionais", as que têm dois homens ou duas mulheres com seus filhos e filhas, as que são formadas apenas por mães com seus filhos e várias outras. Entre as causas dessas mudanças, estão a queda da fecundidade, o envelhecimento da população, divórcios, casamentos, novos arranjos familiares e maternidade postergadas. (MELO; THOMÉ, 2018, p. 87).

Conforme anteriormente tratado, Marri e Wajnman (2007) em sua pesquisa ressaltaram justamente que nas famílias em que as esposas são de fato provedoras, ainda é atribuído a elas o trabalho doméstico no cuidado com o lar, papel de mãe, papel de esposa, entre outros. Algo implicitamente arraigado sobre o padrão de família e o papel social de cada um dos sexos que, problematiza-se neste trabalho como presente na percepção das mulheres participantes desta pesquisa que não se consideram como provedoras da família.

Ainda assim, a sociedade brasileira perdura arraigada com a cultura patriarcalista estabelecida como padrão social, conduzindo à internalização dos determinados papéis na sociedade. Como sinaliza Fleck e Wagner (2003) o modelo de família tradicional da classe média brasileira acompanhava uma tendência mundial em que havia uma clara divisão de papéis: o homem, o patriarca, com o papel de prover a família com trabalho remunerado, enquanto a mulher assumia os afazeres da vida familiar.

Vale ressaltar, ainda, que os dados foram obtidos por meio de pesquisa quantitativa, não sendo possível caracterizar as razões exatas que cada mulher trabalhadora expôs no questionário no seu enquadramento como contribuinte na família. A falta de dados qualitativos complementares a esta pesquisa é que estimulou a problematização da categorização dada por essas mulheres sobre a contribuição financeira de seu trabalho em suas famílias.

\section{CONSIDERAÇ̃̃ES FINAIS}

Os dados apresentados neste estudo demonstraram que entre os participantes analisados há parcela de mulheres trabalhadoras do Município de Parauapebas, no Estado do Pará, que contribui financeiramente no rendimento total da família como provedora e/ou contribuinte. A análise desta percepção é indissociável do contexto cultural, político e histórico da sociedade brasileira no qual essas mulheres estão inseridas e do papel social que é relegado a elas e a divisão sexual do trabalho.

O fato da maioria das mulheres solteiras se caracterizarem como contribuintes gera inúmeros questionamentos acerca da percepção de independência financeira, se elas constituem famílias mo- 
noparentais, se moram com os pais ou sozinhas, entre outros, aspectos estes que revelariam o caminho da percepção socioeconômica de ser provedora ou contribuinte.

Assim como, a obtenção de dados em relação à renda dessas famílias, do homem e da mulher, para caracterizar em aspectos econômicos quantitativos quem é provedor e quem é contribuinte, e, assim contrastar com a percepção do papel social de cada um deles.

Melo e Thomé (2018) ressaltaram o aumento de arranjos familiares comandados por mulheres ou de famílias em que há participação efetiva das mulheres no mercado de trabalho, gerando uma elevação no número de mulheres contribuintes, superando hoje $40 \%$ da participação do rendimento familiar. Tal dado relevante não é automaticamente considerado na percepção: de como a mulher enxerga seu papel econômico e social na composição da renda de sua família.

Apesar de se tratar de um processo lento de transformações e a análise empreendida ser voltada particularmente para a percepção das mulheres, deve-se considerar o que Melo, Considera e Di Sabatto (2007) discutem que as mudanças nos papéis femininos nas últimas décadas geraram, por conseguinte, transformações nos papéis masculinos, uma vez que os papéis de cada ator social são desempenhados em interação constante, se um muda o outro muda também.

Como perspectiva para novas pesquisas, a ampliação da amostra e de uma abordagem mista (quantitativa e qualitativa) com o objetivo de investigar as motivações das percepções das mulheres trabalhadoras poderiam indicar as razões para a percepção auferida nesta pesquisa.

Por fim, compreende-se que este tipo de reflexão não é só da necessidade de maior investimento econômico em políticas públicas direcionadas ao mercado de trabalho da mulher ou do crescimento da participação econômica da mulher na composição da renda familiar, mas que a percepção cultural que estas têm da sua participação na renda familiar. Tal reflexão reflete o lugar que ela compreende ser destinada a ela e, que se sustenta sobretudo, de padrões culturais no qual as relações de poder de um gênero sobre outro impõe o papel social de cada um e por isso, necessita ser problematizado.

\section{REFERÊNCIAS}

ARAÚJo, Anna Bárbara. Gênero no mundo do trabalho. Resenha. Cadernos Pagu, n. 51, 2017.

ARRIGHI, B.; MAUME, J. R. D. Workplace subordination and men's avoidance of housework. Journal of family issues, n. 21, v. 4, p. 464-487, 2000.

BABIUK, Josué da Graciele Alves. Famílias monoparentais femininas, políticas públicas em gênero e raça e serviço social. XIV Congresso Brasileiro de Assistentes Sociais, Águas de Lindoia/SP, 2013. Comunicação Oral.

BERTOLINI, L. B. A. Relações entre o trabalho da mulher e a dinâmica familiar. Congresso de Psicologia Clínica, 1, 2001. Anais [...], São Paulo: Universidade Presbiteriana Mackenzie, 2001. 
BRASIL. Presidência da República. Secretaria de Políticas para as Mulheres. Relatório anual socioeconômico da mulher - RASEAM. $1^{\text {a }}$ Impressão. Brasília: Secretaria de Políticas para as Mulheres, março de 2015.

BRASIL. Instituto Brasileiro de Geografia e Estatísica - IBGE. Estatísticas de Gênero: indicadores sociais das mulheres no Brasil. Estudos e Pesquisas. Informação demográfica e socioeconômica, n. 38, 2018.

FLECK, Ana Cláudia; WAGNER, Adriana. A mulher como a principal provedora do sustento econômico familiar. Psicologia em Estudo, v. 8, n. esp., p. 31-38, 2003.

GARCIA, S. A. F. Satisfação e insatisfação conjugal das mulheres executivas. Congresso de Psicologia Clínica, 1 2001. Anais [...], São Paulo: Universidade Presbiteriana Mackenzie, 2001.

HÉBETTE, Jean. Cruzando a fronteira: 30 anos de estudo do campesinato na Amazônia. Volume I. Belém: Editora Universitária UFPA, 2004.

HIRATA, Helena; KERGOAT, Daniele. A classe operária tem dois sexos. Estudos feministas, n. 1, Ano 2, p. 93-100, $1^{\circ}$ semestre de 1994.

MARRI, Izabel G.; WAJNMAN, Simone. Esposas como principais provedoras de renda familiar. Revista Brasileira de Estudos Populacionais, São Paulo, v. 24, n. 1, p. 19-35, jan./jul. 2007.

MELO, Hildete P. de; CONSIDERA, Cláudio M.; DI SABBATO, Alberto. Os afazeres domésticos contam. Economia e Sociedade, v. 16, n. 31, p. 435-454, dez. 2007.

MELO, Hildete P. de; THOMÉ, Débora. Mulheres e poder: histórias, ideias e indicadores. Rio de Janeiro: FGV Editora, 2018.

MONTALI, Lilia. Provedoras e co-provedoras: mulheres-cônjuge e mulheres-chefe de família sob a precarização do trabalho e desemprego. Revista Brasileira de Estudos Populacionais, v. 23, n. 2, p. 223-245, jul./dez. 2006.

NARVAZ, Martha G.; KOLLER, Sílvia H. Famílias e patriarcado: da prescrição normativa à subversão criativa. Psicologia \& Sociedade, v. 18, n. 1, p. 49-55, jan./abr. 2006.

OIT - Organização Internacional do Trabalho. Perspectivas sociales y del empleo en el mundo: Tendencias 2018. Ginebra: OIT, 2018. Disponível em: https://www.ilo.org/wcmsp5/groups/public/--dgreports/---dcomm/---publ/documents/publication/wcms_631466.pdf. Acesso em: 11 nov. 2018. 
PRESTON, V.; ROSE, D., NORCLIFFE, G; HOLMES, J. Shift work, childcare and domestic work divisions of labour in Canadian paper mill communities. Gender, place and future, n. 7, v. 1, p. 5-29, 2000.

ROCHA, Avone J. Araújo. À margem do projeto ferro carajás: uma pequena contribuição à história social e cultural de Parauapebas (1980-2004). Goiânia: Kelps, 2018.

ROCHA-COUTINHO, M. L. Dos contos de fadas aos superheróis: mulheres e homens brasileiros reconfiguram identidades. Psicologia Clínica, n. 12, v. 2, p. 65-82, 2000.

SAMPIERE, R. H., COLLADO, C.F., LUCIO, M.P.B. Metodologia de pesquisa. 3. ed. Porto Alegre: Penso, 2013. 
1 Doutora em Psicologia pela Universidade Federal do Pará - UFPA; Professora Adjunta de Humanização da Universidade Federal Rural da Amazônia - UFRA.

E-mail: danireispara@ufra.edu.br

2 Mestra em Agriculturas Familiares e Desenvolvimento Sustentável pela Universidade Federal do Pará - UFPA; Professora Assistente de Direito e Legislação da Universidade Federal da Amazônia - UFRA.

E-mail: josilene.mendes@ufra.edu.br

3 Especialista em Direito Público pela Universidade Cândido Mendes; Delegada da Polícia Civil do Estado do Pará;

Professora de Direito Constitucional.

E-mail: delegadaanacarolina@gmail.com 